\title{
Coupling of a Novel TIMP3 Peptide to Carboxypeptidase G2 for Pro-Drug Activation at the Tumour Site
}

\author{
Mohammed S. Aldughaim 1,2,*, Fatimah Alsaffar ${ }^{2,3}$ and Michael D. Barker ${ }^{2}$ \\ 1 Research Centre, King Fahad Medical City, P.O. Box 59046, Riyadh 11525, Saudi Arabia \\ 2 Department of Oncology and Metabolism, Medical School, University of Sheffield, Beech Hill Rd, \\ Sheffield S10 2RX, UK; falsaffar@gc.edu.sa (F.A.); m.barker@sheffield.ac.uk (M.D.B.) \\ 3 Department of Clinical Laboratory Sciences, Alghad International Colleges for Applied Medical Sciences, \\ Dammam 32423, Saudi Arabia \\ * Correspondence: maldughaim@kfmc.med.sa; Tel.: +96-61-1288-9999 (ext. 10834)
}

Citation: Aldughaim, M.S.; Alsaffar, F.; Barker, M.D. Coupling of a Novel TIMP3 Peptide to Carboxypeptidase G2 for Pro-Drug Activation at the Tumour Site.

Molecules 2021, 26, 625.

https://doi.org/10.3390/

molecules26030625

Academic Editors: George Kokotos and Iola F. Duarte

Received: 19 November 2020

Accepted: 19 January 2021

Published: 25 January 2021

Publisher's Note: MDPI stays neutral with regard to jurisdictional claims in published maps and institutional affiliations.

Copyright: (c) 2021 by the authors. Licensee MDPI, Basel, Switzerland. This article is an open access article distributed under the terms and conditions of the Creative Commons Attribution (CC BY) license (https:// creativecommons.org/licenses/by/ $4.0 /)$.

\begin{abstract}
Broad-spectrum cytotoxic drugs have been used in cancer therapy for decades. However, their lack of specificity to cancer cells often results in serious side-effects, limiting efficacy. For this reason, antibodies have been used to attempt to specifically target cytotoxic drugs to tumours. One such approach is antibody-directed enzyme prodrug therapy (ADEPT) which uses a tumour-directed monoclonal antibody, coupled to an enzyme, to convert a systemically administered non-toxic prodrug into a toxic one only at the tumour site. Among the main drawbacks of ADEPT is the immunogenicity of the antibody-enzyme complex, which is exacerbated by slow clearance due to size, hence limiting repeated administration. Additionally, the mono-specificity of the antibody could potentially result in drug resistance with repeated administration. We have identified a novel short peptide sequence, p700, derived from a human tissue inhibitor of metalloproteinases-3 (TIMP-3), which binds to and inhibits a number of tyrosine kinase growth factor receptors (VEGFRs1-3, FGFRs 1-4 and PDGFR $\alpha$ ) which are known to be upregulated in many tumours and tumour vasculature. In this report, we fused p700 to His-tagged, codon-optimised, carboxypeptidase G2 (CPG2). CPG2 is a bacterial enzyme used in ADEPT, which activates potent nitrogen-mustard pro-drugs by removal of an inhibitory glutamic acid residue. Recombinant CPG2-p700 was highly expressed in Escherichia coli and successfully purified by nickel affinity chromatography. Biolayer interferometry showed that CPG2-p700 had a 100-fold increase in binding affinity for VEGFR2 compared with CPG2 alone and retained its catalytic activity, as determined by methotrexate cleavage. In the presence of CPG2-p700, the ZD2676P pro-drug showed significant cytotoxicity for 4T1 cells compared with prodrug alone or CPG2 alone. p700 is, therefore, a potentially useful alternative to monoclonal antibodies for enzyme pro-drug therapy and could equally be used for effective delivery of other cytotoxic drugs to tumour tissue.
\end{abstract}

Keywords: angiogenesis; carboxypeptidase G2; TIMP3; VEGFR2

\section{Introduction}

Broad-spectrum cytotoxic drugs, such as nitrogen mustards, have been the mainstay of cancer therapy for many years. However, such drugs not only target cancer cells but all proliferating cells, resulting in severe side-effects, which limits dosage and potential efficacy in the long-term [1]. Many mechanisms have been used to target chemotherapeutics specifically to the cancer sites, including antibody directed enzyme prodrug therapy (ADEPT) [2-4]. In ADEPT, enzymes that convert prodrugs to active drugs are first targeted to the cancer site by a tumour-specific monoclonal antibody. After clearance of the enzyme from normal tissue, the prodrug is administered to be activated at the cancer site [5]. ADEPT is advantageous due to the accumulation of the enzyme-antibody conjugate within the tumour vasculature after clearance from normal tissues. 
A Pseudomonas aeruginosa strain RS-16-derived enzyme, carboxypeptidase G2 (CPG2 or glucarpidase), has been used in this staged therapy [6]. This is partly because its activity is not found in humans, reducing the chance of toxicity to healthy tissue, as the prodrug will be activated only by the localized exogenous enzyme. This zinc-dependent enzyme naturally catalyses the hydrolysis of the C-terminal glutamic acid residue of folic acid and synthetic folate analogues such as the cancer chemotherapy agent, methotrexate (MTX). For this reason, CPG2 is sometimes used clinically for clearing excess MTX in patient blood after high dose therapy to control its side effects [7,8]. In ADEPT, CPG2 can be used to activate prodrugs such as nitrogen mustard L-glutamate prodrugs into nitrogen mustards, which cross-link DNA leading to apoptosis [9].

However, there are several drawbacks to ADEPT that have prevented its successful application in the clinic. Most importantly, the host immune response to this conjugate is a major problem in the successful application of ADEPT preventing repeat dosage and leading to neutralisation of the antibody $[3,4]$. This is exacerbated by slow clearance rates of the complex. Prolonged circulation times are also a major issue, as the enzyme must be cleared from the circulation prior to pro-drug administration to avoid off target activation. While antibodies can be humanised, this is an expensive and time-consuming process. Additionally, antibodies are mono-specific, and tumours often rapidly evolve to lose expression of the target molecule. While several different antibodies could be used, this increases the complexity and cost, particularly if humanisation is required [10].

As an alternative to using monoclonal antibodies, in this study, we utilised a short, tumour-specific peptide, p700, to target the enzyme CPG2 to tumours. p700 is a short 16 amino acid fragment derived from the $C$ terminal domain of tissue inhibitor of metallo proteinase-3 TIMP3, which potently inhibits VEGFR2. Unlike the parent molecule, however, p700 exhibits a broader binding specificity for other growth factor receptors such as VEGFR1, VEGFR3, PDGFR $\alpha$, FGFR1, FDFR2 $\alpha$, FDFR3 and FDFR4, all of which are highly expressed in tumours or tumour vasculature [11]. Using this peptide instead of a monoclonal antibody has several potential advantages. Firstly, the peptide is derived from a human extracellular protein and is not expected to be immunogenic, even in mice which share the same sequence at this site. Secondly, the small size of the peptide should enable much more rapid clearance of the complex, further reducing any potential immunogenicity and non-targeted prodrug activation. Lastly, the peptide targets multiple receptors on both tumours and tumour vasculature, greatly decreasing the likely development of drug resistance.

\section{Methods}

\subsection{Synthesis of CPG2 Codon-Optimized Synthetic Gene}

A CPG2 gene bearing a $3^{\prime}[\mathrm{His}]_{5}$ tag and codon optimised for expression in E. coli (Goda et al. 2009) was synthesised by Eurofins Genomics (UK). However, the second AgeI site at base 1050 was engineered out to leave a single AgeI site at position 106, while 5' NdeI and $3^{\prime}$ HindIII and NotI restriction sites were added to facilitate cloning into pET28a bacterial expression vector. This was supplied in a kanamycin resistant cloning vector; pEX-K4. The p700 peptide sequence with $5^{\prime}$ NdeI sites was also synthesised by Eurofins, including a [Gly $\left.{ }_{4} \mathrm{Ser}\right]_{4}$ linker and the CPG2 sequence up to the AgeI site and supplied in an ampicillin-resistant cloning vector, $\mathrm{pEX}-\mathrm{A} 2$. All the plasmids were transformed into $\alpha$-Select chemically-competent E. coli, followed by mini-prep purification (Qiagen Manchester, UK) following the manufacturer's instructions.

\subsection{Sub-Cloning of the Codon Optimised CPG2-His Gene into pET28a and Insertion of the p700 Peptide Sequences \\ Codon-optimised CPG2-His (approximately $1200 \mathrm{bp}$ in length) was excised from pEX-K4 by digestion with NdeI and NotI and ligated into the bacterial expression vec- tor, pET28a, to form an unmodified CPG2-His-pET28a expression construct. The p700- [Gly $\left._{4} \mathrm{Ser}\right]_{4}$ sequence was then excised from the $\mathrm{pEX}-\mathrm{A} 2$ vector and cloned into the NdeI}


and AgeI restriction sites of the CPG2-His-pET28a by cutting both constructs with these enzymes to generate a p700-[Gly ${ }_{4}$ Ser $]_{4}$-CPG2-His-pET28a expression construct (refer to Supplementary Data, S1). Both constructs were transformed into $\alpha$-Select chemically competent E. coli (Bioline, London, UK). Miniprep and maxiprep plasmid purifications (Qiagen, Manchester, UK) were then performed.

\subsection{Small Scale Induction of CPG2-Only and CPG2 Fusion Protein Expression}

Following verification of the two CPG2 constructs' DNA sequences, plasmid DNA was transformed into E. coli BL21 (DE3) grown on LB agar plates containing $50 \mu \mathrm{g} / \mathrm{mL}$ kanamycin and $0.2 \%$ glucose. A single colony was then transferred to a tube containing $10 \mathrm{~mL}$ LB broth and $50 \mu \mathrm{g} / \mathrm{mL}$ kanamycin and incubated overnight at $37^{\circ} \mathrm{C}$ on a rotating shaker.

For induction, $9 \mathrm{~mL}$ of these cultures was then inoculated into $100 \mathrm{~mL}$ of LB broth (plus antibiotic) and further incubated until the optical density (OD) reached 0.5-0.6. Isopropyl$\beta$-D-thiogalactopyranoside (IPTG) was then added at a final concentration of $1 \mathrm{mM}$ to induce protein expression. This was followed by further incubation, and samples $(1 \mathrm{~mL})$ were then removed at 1, 2, 3 and $4 \mathrm{~h}$ post-induction.

\subsection{Protein Detection by SDS-PAGE and Coomassie Brilliant Blue Staining}

Pellets obtained by centrifuging the above cultures at $14 \times 10^{3} \times g$ were re-suspended in $50 \mu \mathrm{L} \mathrm{dH} \mathrm{dH}_{2} \mathrm{O}, 10 \mu \mathrm{L}$ of which was diluted with an equivalent volume of $2 \times$ Laemmli sample buffer (Bio-Rad ${ }^{\circledR}$ Kidlington, UK) and $1 \mu \mathrm{L}$ of $1 \mathrm{M}$ dithiothreitol (DTT). Sample tubes were heated at $95{ }^{\circ} \mathrm{C}$ for $5 \mathrm{~min}$, after which the samples were transferred to QIAshredder tubes and centrifuged at $14 \times 10^{3} \times g$ for $2 \mathrm{~min}$ to remove debris and shear the genomic DNA.

An amount of $15 \mu \mathrm{L}$ of the above samples was separated by SDS-PAGE on a 10\% gel, followed by staining with colloidal Coomassie G250 stain (National Diagnostics) and then imaging using a Bio-Rad ${ }^{\circledR}$ Gel DOC ${ }^{\mathrm{TM}}$ EZ imager.

\subsection{Solubility Test of Recombinant Proteins}

A solubility test was carried out to determine whether the expressed proteins were in the soluble fraction (supernatant) or the insoluble fraction (pellet) of the bacterial cell lysates. Briefly, IPTG-induced E. coli-expressing CPG2 and CPG2-fusion proteins were grown in LB broth supplemented as above for $4 \mathrm{~h}$, after which a $1 \mathrm{~mL}$ sample was taken and centrifuged at $14 \times 10^{3} \times g$ for $2 \mathrm{~min}$. The pellet was resuspended in $2 \mathrm{~mL} \mathrm{of} \mathrm{dH}_{2} \mathrm{O}$ containing Roche Protease Inhibitor Cocktail (1 tablet in $50 \mathrm{~mL}$ ), followed by $40 \mu \mathrm{L}$ of lysozyme $(10 \mathrm{mg} / \mathrm{mL})$, mixed and then incubating on ice for $20 \mathrm{~min}$. Next, $80 \mu \mathrm{L}$ of sodium deoxycholate $(25 \mathrm{mg} / \mathrm{mL})$ was added followed by incubation on ice as above. The cells were lysed by sonication ( 4 cycles at $10 \mathrm{~s} /$ cycle) on ice. The lysate was centrifuged at $14 \times 10^{3} \times g$ for $25 \mathrm{~min}\left(\right.$ at $4^{\circ} \mathrm{C}$ ), and the collected pellet was resuspended in $2 \mathrm{~mL} \mathrm{dH}_{2} \mathrm{O}$. Whole cell lysate, supernatant and resuspended pellet were analysed on a Coomassie Blue stained SDS-PAGE gel.

\subsection{Large Scale Induction of Recombinant CPG2 Expression}

Large scale cultures of transformed BL21 cells were prepared as before, but each starter culture was diluted into $1 \mathrm{~L}$ of LB broth containing $50 \mu \mathrm{g} / \mathrm{mL}$ kanamycin and grown at $37{ }^{\circ} \mathrm{C}$ with shaking. At an OD of $0.5-0.6$, the cells were induced with IPTG to a $1 \mathrm{mM}$ final concentration with a $1 \mathrm{~mL}$ sample taken before induction. Cells were incubated for a further $3-4 \mathrm{~h}$ at $37^{\circ} \mathrm{C}$ with shaking. The cells were harvested at $5500 \times \mathrm{g}$ for $15 \mathrm{~min}$ at $4{ }^{\circ} \mathrm{C}$. The pellets were processed as described below.

\subsection{Whole Bacterial Cell Lysis and Separation into Soluble and Insoluble Fractions}

Pellets from the large-scale expression (1 L culture) were resuspended in $20 \mathrm{~mL}$ Tris buffer (20 mM Tris, $137 \mathrm{mM} \mathrm{NaCl}, 1 \mathrm{mM}$ EDTA pH 7.6) containing protease inhibitor cocktail (Roche, Welwyn Garden City, UK). Cells were lysed with $400 \mu \mathrm{L}$ of $10 \mathrm{mg} / \mathrm{mL}$ 
lysozyme (final concentration of $200 \mu \mathrm{g} / \mathrm{mL}$ ) and incubated on ice for $30 \mathrm{~min}$. An amount of $800 \mu \mathrm{L}$ of $25 \mathrm{mg} / \mathrm{mL}$ sodium deoxycholate detergent was added to the lysate and incubated on ice for $20 \mathrm{~min}$, followed by four $1 \mathrm{~min}$ sonication cycles. Cell lysates were then centrifuged at $15,000 \times g$ for $25 \mathrm{~min}$ at $4{ }^{\circ} \mathrm{C}$ and the supernatants and pellets retained.

\subsection{Inclusion Body Preparation}

2.8.1. Insoluble Fraction

The above pellets were resuspended in $20 \mathrm{~mL}$ of Tris buffer with urea $(20 \mathrm{mM}$ Tris, $137 \mathrm{mM} \mathrm{NaCl}, 2 \mathrm{M}$ urea, $1 \mathrm{mM}$ EDTA pH 8) and mixed thoroughly. Aliquots of $50 \mu \mathrm{L}$ of the suspension were retained for SDS-PAGE analysis.

\subsubsection{Washes}

The remaining cell suspensions were then centrifuged at $15,000 \times g$ for $30 \mathrm{~min}$. The supernatants (Wash 1) were collected and the pellets resuspended in Tris buffer with urea for three other rounds of centrifugation. The second supernatants were also collected for SDS-PAGE analysis.

\subsubsection{Inclusion Body}

The final pellet (inclusion body) was transferred into a microfuge tube and re-suspended in $50 \mu \mathrm{L}$ of $\mathrm{dH}_{2} \mathrm{O}$ for SDS-PAGE analysis.

\subsection{CPG2 Purification from the Insoluble Fraction by $\mathrm{Ni}^{2+}{ }_{-N T A}$ Chromatography \\ 2.9.1. Preparation of $\mathrm{Ni}^{2+}$ Column}

The $\mathrm{Ni}^{2+}$-NTA columns (Sigma-Aldrich, Gillingham, UK) were initially equilibrated with $20 \mathrm{~mL} \mathrm{dH_{2 }}$ O running under gravity followed by charging with $10 \mathrm{~mL}$ of $10 \mathrm{mM} \mathrm{NiCl}_{2}$, and then $20 \mathrm{~mL}$ of water running under gravity. The column was then washed with $10 \mathrm{~mL}$ of wash buffer 1 ( $20 \mathrm{mM}$ Tris, $137 \mathrm{mM} \mathrm{NaCl}, 2 \mathrm{M}$ urea; $\mathrm{pH}$ 8).

\subsubsection{Protein Purification}

Washes 1-4 were pooled together (making a total of approximately $60 \mathrm{~mL}$ ) and $300 \mu \mathrm{L}$ of $4 \mathrm{M}$ imidazole added to a final concentration of $20 \mathrm{mM}$ and loaded onto the $\mathrm{Ni}^{2+}$-NTA columns. Columns were then washed with $10 \mathrm{~mL}$ of filtered wash buffer $2(20 \mathrm{mM}$ Tris, $137 \mathrm{mM} \mathrm{NaCl}, 1 \mathrm{M}$ urea; $\mathrm{pH} \mathrm{8}$ ) and the flow through collected each time for SDS-PAGE analysis to ensure that the protein had bound to the columns.

\subsubsection{Elution}

His tagged proteins bound to the columns were then eluted with $10 \mathrm{~mL}$ elution buffer 1 ( $20 \mathrm{mM}$ tris, $137 \mathrm{mM} \mathrm{NaCl}, 500 \mathrm{mM}$ urea, $200 \mathrm{mM}$ imidazole; $\mathrm{pH}$ 8). The eluents were collected in $1 \mathrm{~mL}$ fractions for SDS-PAGE analysis. Further elution was performed by addition of $10 \mathrm{~mL}$ elution buffer $2(20 \mathrm{mM}$ Tris, $137 \mathrm{mM} \mathrm{NaCl}, 500 \mathrm{mM}$ urea, $500 \mathrm{mM}$ imidazole; $\mathrm{pH}$ 8), and samples collected as above.

\subsection{Enzyme Activity Assay}

Recombinant CPG2 fusion protein activity was assessed using methotrexate (MTX) as substrate with a modified protocol of Goda, Rashidi [5]. Briefly, $1 \mathrm{~mL}$ of $100 \mathrm{mM}$ Tris$\mathrm{HCl} \mathrm{pH} 7.3$ containing $0.2 \mathrm{mM} \mathrm{ZnSO}_{4}$ and $60 \mu \mathrm{M}$ of MTX was added to a cuvette and incubated at $37^{\circ} \mathrm{C}$ for $5-10 \mathrm{~min}$. Purified recombinant CPG2 fusion protein was then added (final concentration of $16 \mu \mathrm{g} / \mathrm{mL}$ ) to the cuvettes, which were placed directly into a spectrophotometer, maintained at $37^{\circ} \mathrm{C}$. Tris buffer without MTX was used as background control, and decrease in absorbance at $320 \mathrm{~nm}$ was measured at $5 \mathrm{~min}$ intervals. 


\subsection{Assessment of Zinc-Dependence of Recombinant CPG2-Fusion Protein Enzyme Activity}

Zinc-dependence of the purified recombinant CPG2 fusion proteins for enzyme activity was evaluated as described above in the presence of $\mathrm{ZnSO}_{4}$ or in its absence with the addition of $10 \mathrm{mM}$ EDTA as a zinc chelating agent.

\subsection{Kinetic Analysis of CPG2-p700 Binding to VEGFR2 by Biolayer Interferometry (BLI)}

Biolayer interferometry (BLI), using the BLItz ${ }^{\circledR}$ system (ForteBio, Göttingen, Germany), was used for real-time kinetic analysis of the interaction between recombinant CPG-p700 and its ligand, VEGFR2, according to the manufacturer's instructions.

Briefly, protein A-coated probes were hydrated by soaking in PBS for at least $10 \mathrm{~min}$ and then loaded onto the biosensor mount. An initial baseline was established by lowering the probe into $250 \mu \mathrm{L}$ of PBS in the tube holder for $60 \mathrm{~s}$. VEGFR2-Fc ligand solution (R\&D Systems), $5 \mu \mathrm{L}$ at a concentration of $250 \mu \mathrm{g} / \mathrm{mL}$, was then loaded into the drop holder and the biosensor inserted for $300 \mathrm{~s}$. A further baseline step was then established before the CPG2 recombinant proteins (CPG2 or CPG2-p700) were introduced into the drop holder for the association and dissociation steps. Control runs were performed with only PBS and only VEGFR2-Fc (no recombinant CPG2 proteins added) for comparison.

The experiment was then repeated five times with subsequent sample (CPG2 or CPG2p700) concentrations ranging from $600 \mathrm{nM}$ to $10 \mu \mathrm{M}$. The binding affinity (Kd) was then calculated by the BLItz ${ }^{\circledR}$ software based on the binding signal $(\mathrm{nm})$, sample concentration and molecular weight.

\subsection{Cytotoxicity Assay}

The ability of the purified CPG2 recombinant proteins to activate the nitrogen mustard pro-drug ZD2676P ((2S)-2-[(4-[bis(2-iodoethyl)amino]phenoxy-carbonyl)amino] pentanedioic acid hydroiodide-High Force Research, Durham, UK) was evaluated using a cytotoxicity assay with the mouse breast cancer cell line 4T1.

$4 \mathrm{~T} 1$ cells were seeded into three 96-well plates at a density of $2 \times 10^{3}$ cells per well and then cultured overnight at $37^{\circ} \mathrm{C}$. Three 96-well plates were prepared, one with $100 \mu \mathrm{L}$ medium containing recombinant codon-optimised CPG2-only protein at $16 \mu \mathrm{g} / \mathrm{mL}$ maximal enzyme activity concentration, a second containing recombinant CPG2-p700 at the same concentration $(16 \mu \mathrm{g} / \mathrm{mL})$ and a third with $100 \mu \mathrm{L}$ fresh medium only. The plates were incubated for $4 \mathrm{~h}$ at $37^{\circ} \mathrm{C}$ to allow binding of the CPG2-p700. The media in all wells were then aspirated completely and the cells washed twice with PBS to remove any unbound CPG2 residues.

Triplicate wells of the cells were exposed to varying concentrations of ZD2676P prodrug ranging from 2 to $14 \mu \mathrm{M}$ concentrations and incubated at $37^{\circ} \mathrm{C}$ for one hour (as recommended by the pro-drug supplier). The media were aspirated, replaced with fresh growth medium and the plates incubated for 3-4 days before $20 \mu \mathrm{L}$ of MTS solution (CellTiter $96{ }^{\circledR} \mathrm{AQ}$ ueous One Solution-Promega, Southampton, UK) was added into each well to determine cell viability, according to the manufacturer's protocol. The absorbance of the wells was recorded at $490 \mathrm{~nm}$ with a 96-well plate reader. For each cell line, experiments were repeated three times in six wells of each 96-well plate. Statistical analysis was performed using two-way ANOVA and Bonferroni multi-comparison. Percentage cell viability curves were drawn using GraphPad prism software (v7.0).

\section{Results}

\subsection{Solubility Test}

Solubility testing was carried out to determine whether the CPG2 was expressed predominantly in the cytosol (soluble fraction) or in inclusion bodies (insoluble fraction). After $3 \mathrm{~h}$ of IPTG induction, expression of the CPG2 and CPG2-p700 was found to be minimal in both initial whole cell lysate and in the soluble fraction of the cells which was derived from supernatants of centrifuged whole cell lysate. However, the insoluble fraction 
derived from pellets of centrifuged whole cell lysate showed high expression of the CPG2 and CPG2-p700 proteins (Figure 1).
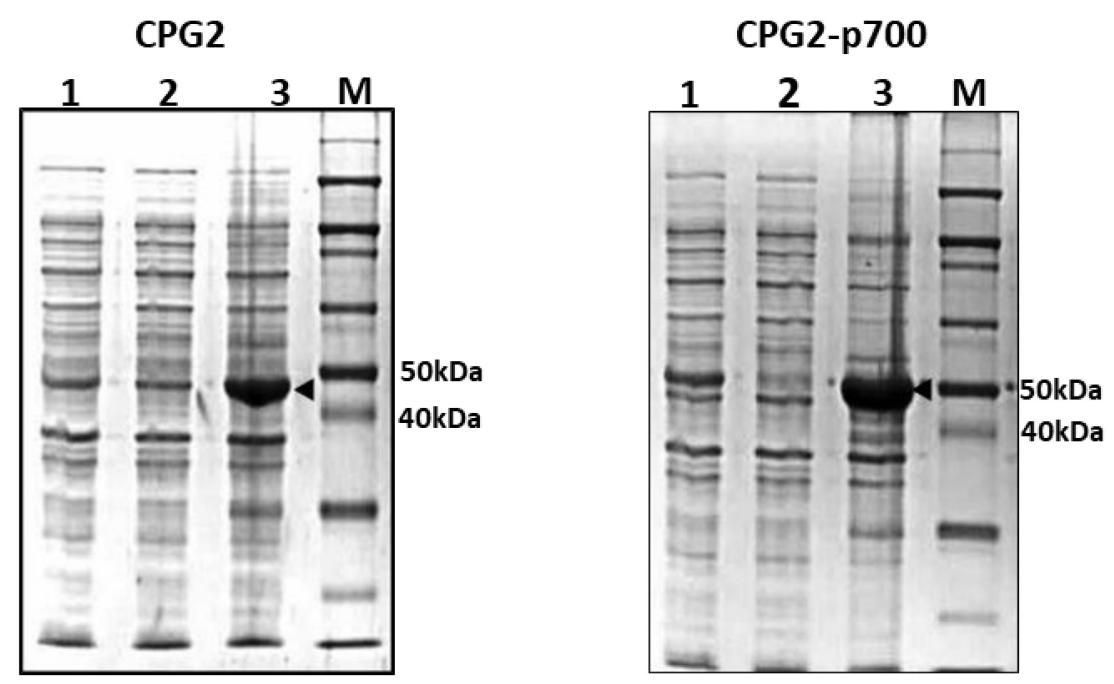

Figure 1. Solubility test to determine localisation of recombinant CPG2 protein expression in BL21 E. coli. Coomassie Blue staining following SDS-PAGE of samples of whole cell lysate (lane 1), supernatant (lane 2) and re-suspended pellet (lane 3) of IPTG induced BL21 E. coli expressing CPG2 and CPG2-p700 proteins, respectively, from left to right, along with protein standards (ladder). The arrowheads indicate over-expressed CPG2 and CPG2-p700 proteins at the expected sizes (45 and $48 \mathrm{kDa}$, respectively) in the re-suspended pellets.

\subsection{Large Scale Expression of CPG2 and CPG2 Fusion Proteins}

After determining that the recombinant proteins were maximally expressed after $3 \mathrm{~h}$, a large-scale IPTG-induced expression of the recombinant proteins was carried out to determine if the expression could be replicated in bulk. As shown by both Coomassie blue staining (Figure 2A) and Western blotting (Figure 2B), there is clear, high-level expression of CPG2 and CPG2-p700 after $3 \mathrm{~h}$.

\subsection{Inclusion Body Preparation for CPG2 and Purification of CPG2 Recombinant Proteins}

The solubility testing confirmed that the recombinant proteins localised almost exclusively to the inclusion bodies of the bacteria which would necessitate extraction of the proteins with a denaturing agent that would permit refolding of functional proteins. Urea is commonly used for this purpose and, in the protocol for CPG2 expression described by Goda, Rashidi [5], the pellets were initially washed in three changes of $2 \mathrm{M}$ urea before complete dissolution in $6 \mathrm{M}$ urea, and so this procedure was replicated here. However, in our case, considerable amounts of relatively pure recombinant proteins were found in the $2 \mathrm{M}$ urea washes, as shown in Figure 3A,B. While most of the protein was still found in the remaining pellets, it was thought that the protein found in the washes may not be fully denatured and would probably be sufficient to carry out initial functional screening assays, while the protein in the remaining pellets would require much more aggressive denaturation, and subsequent renaturation, which may result in loss of function. 


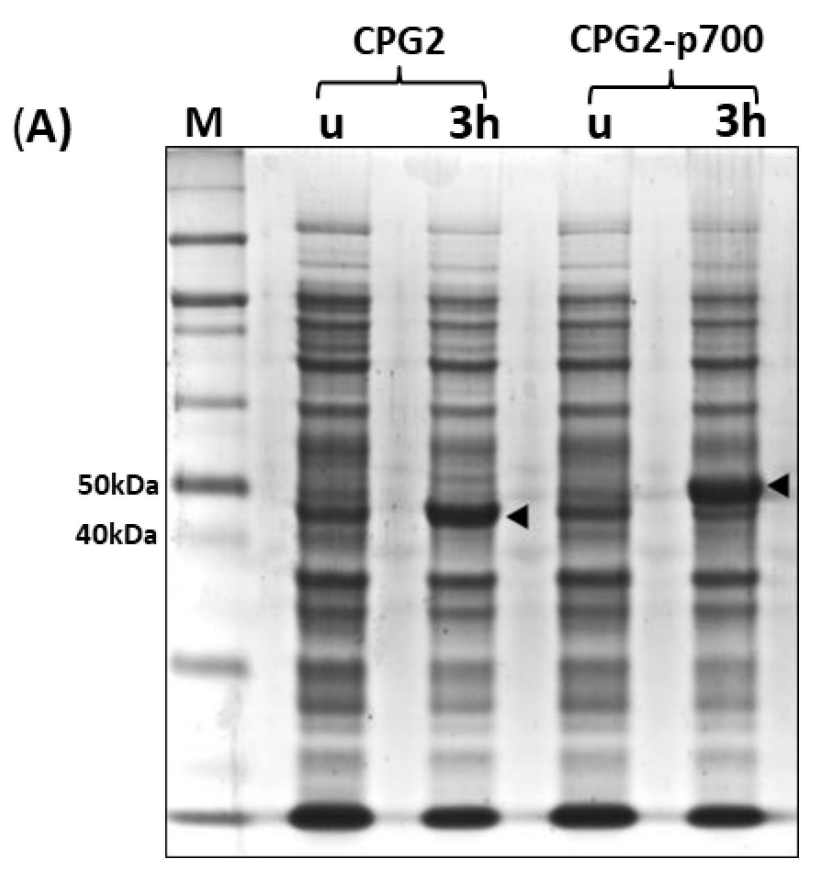

(B)

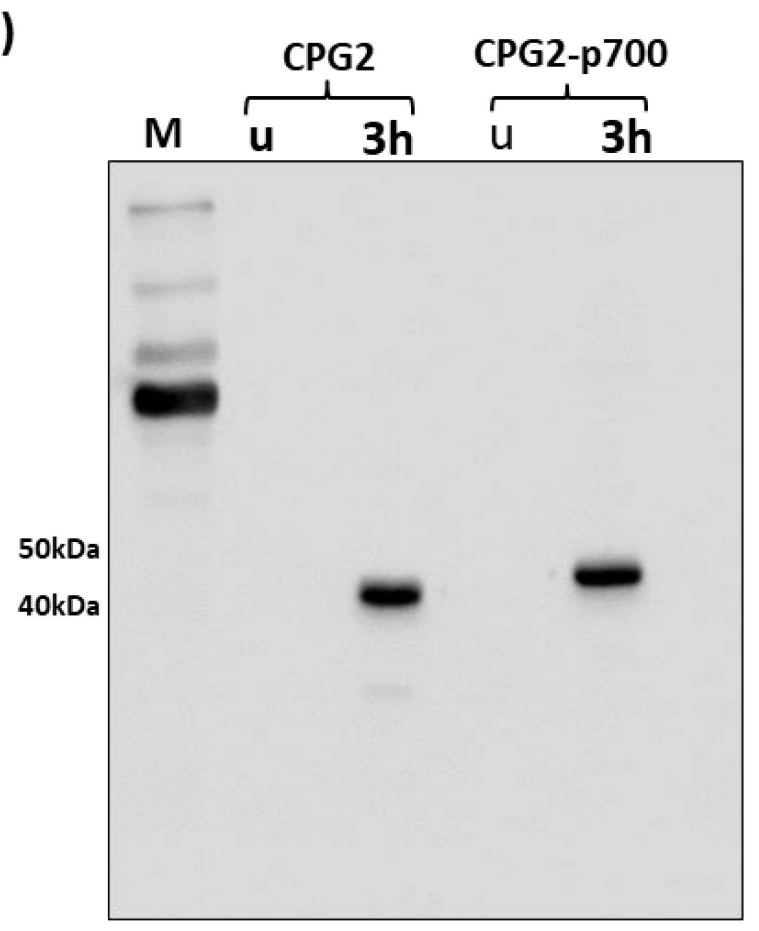

Figure 2. Large-scale expression of CPG2 recombinant proteins in BL21 E. coli. Panel (A) Coomassie blue staining following SDS-PAGE of paired samples (whole cell lysate) taken pre- $(\mathrm{u})$ and $3 \mathrm{~h}$ post-IPTG induction ( $3 \mathrm{~h}$ ) of CPG2, and CPG2-p700 recombinant protein expression, respectively, from left to right, compared with a ladder (extreme left). The arrowheads highlight the protein bands of the expected sizes (45 and $48 \mathrm{kDa}$ ). Panel (B) Western blotting analysis using antihistidine antibody on identical samples corresponding to the top panel, compared with a protein ladder (extreme left). Histidine-tagged recombinant proteins of the expected sizes (45 and $48 \mathrm{kDa}$ ) were detected in post-induction samples, but not in corresponding pre-induction samples. 
(A)

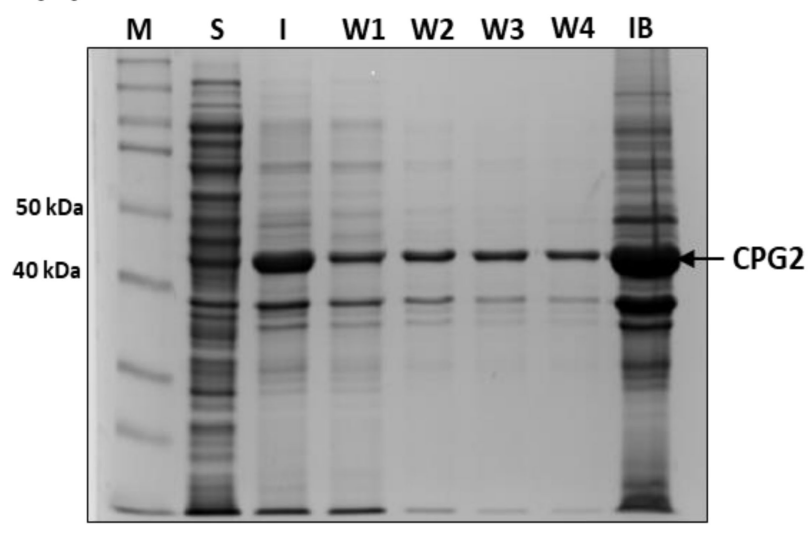

(B)

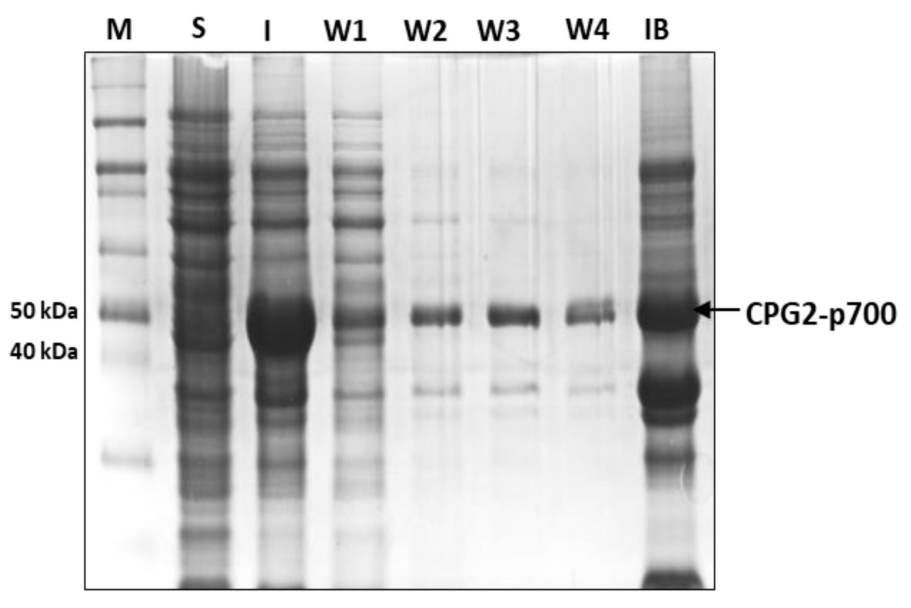

(C)

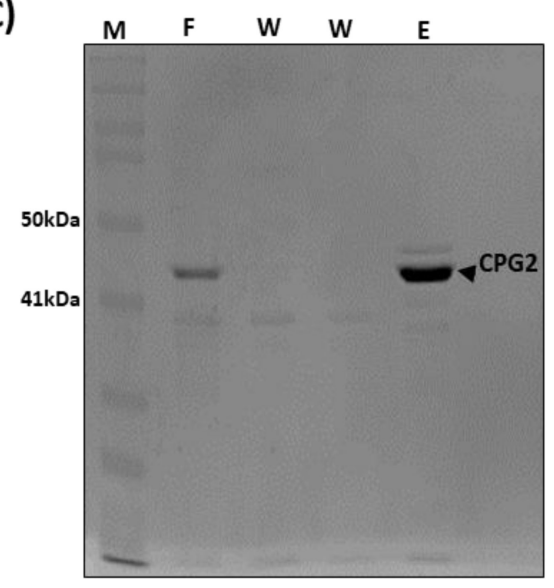

(D)

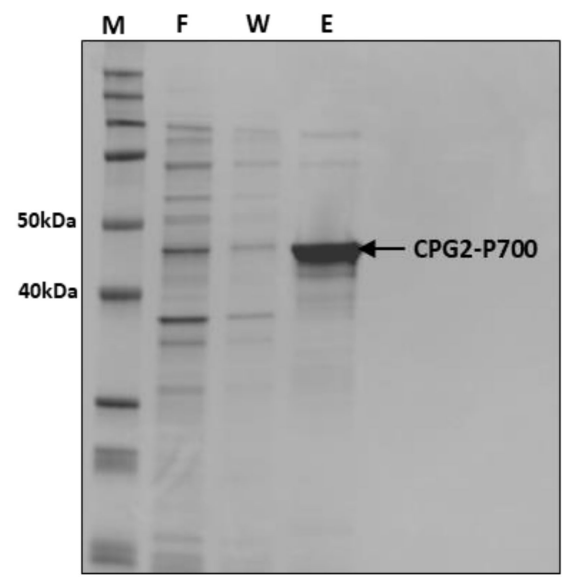

Figure 3. Purification of recombinant CPG2 proteins on nickel-chelate resin from urea washes derived from the insoluble fraction of BL21 E. coli cell lysates. (A) CPG2 and (B) CPG2-p700 coomassie blue stained SDS-PAGE gels. Lanes are of standard protein ladder; soluble fraction; insoluble fraction; four sequential urea washes; and remaining inclusion body, respectively, of IPTG-induced BL21 E. coli cells expressing. Pooled washes (1 to 4) from the insoluble fraction of lysates derived the IPTG-induced BL21 E. coli cells expressing His-tagged recombinant (C) CPG2 and (D) CPG2-p700 (right panel) were purified using a Ni2+ chelate column. Lanes (left to right) represent Coomassie Blue staining following SDS-PAGE of standard protein ladder, initial flow-through, wash and eluent (purified recombinant protein).

As alluded to above, instead of extracting the CPG2 recombinant proteins from the pellets remaining after the urea washes, the recombinant proteins were purified from the four pooled $2 \mathrm{M}$ urea washes using Ni-NTA affinity chromatography. The result of the purification step is shown in Figure $3 \mathrm{C}, \mathrm{D}$, and we were able to acquire sufficient purified protein $(1 \mathrm{mg} / \mathrm{mL})$ for subsequent functional assays.

\subsection{Assessment of the Enzymatic Activity of the Purified Recombinant CPG2proteins}

The catalytic activity of the purified proteins was assessed using a methotrexate (MTX) cleavage assay. As CPG2 is a zinc-dependent enzyme, the assay was carried out in the presence or absence of zinc, and in the presence of zinc and EDTA (a zinc chelator) in order to confirm that any cleavage seen was most likely due to CPG2 and not any other potentially contaminating protein. MTX was used as it is readily cleaved by CPG2 resulting in a reduction in its absorbance at a wavelength of $320 \mathrm{~nm}$ which can be observed spectrophotometrically. Figure 4 shows that both CPG2 and CPG2-p700 were able to metabolise MTX in the presence of zinc, but not in its absence nor in the presence of zinc and EDTA. The rate of breakdown was almost identical between CPG2 and CPG2-p700, 
indicating that the purified enzyme is both functionally active and that the p700 sequence does not interfere with this activity.

\section{(A)}

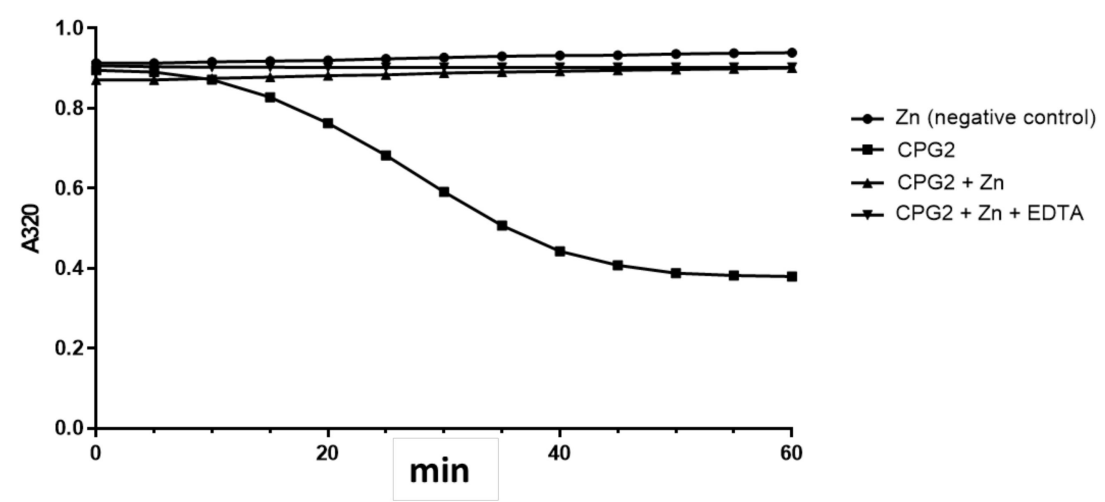

(B)

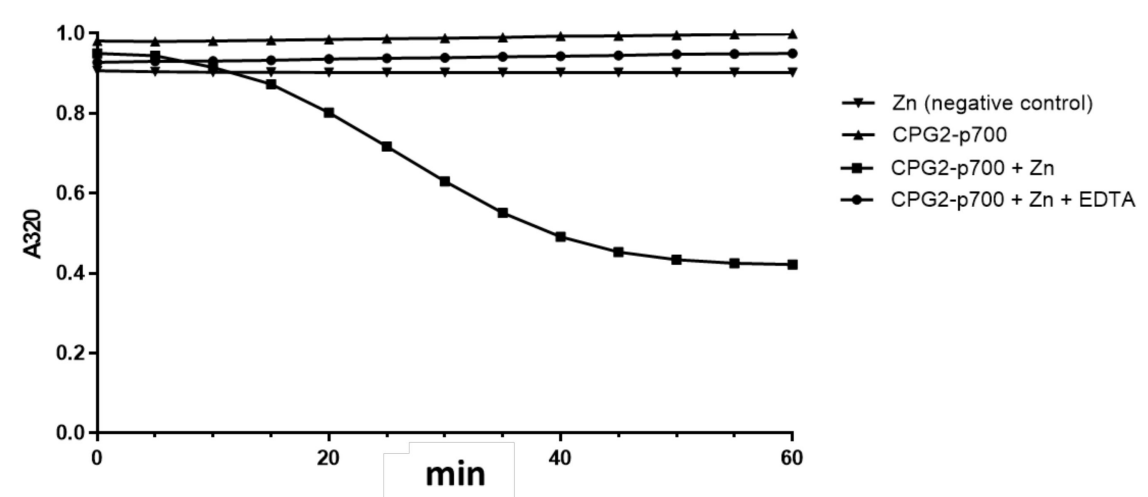

Figure 4. Confirmation of the zinc-dependent enzymatic activity of purified recombinant CPG2 proteins. Recombinant proteins were incubated with methotrexate at $37^{\circ} \mathrm{C}$ for $0-60 \mathrm{~min}$. The absorbance of each reaction at $320 \mathrm{~nm}$ was plotted against time. A similar reduction in absorbance (representing catalysis of MTX) was seen for both CPG2 (A) and CPG2-p700 (B) in the presence of $\mathrm{ZnSO} 4$ but not in its absence nor when the zinc chelating agent, EDTA, was added.

\subsection{Determination of the Ability of CPG2-p700 Recombinant Protein to Bind to VEGFR2 by Biolayer Interferometry}

Biolayer interferometry enables kinetic analysis to be carried out on very small sample volumes and was used to confirm that covalent coupling of p700 to CPG2 did not interfere with its ability to bind to one of its key target receptors, VEGFR2. A VEGFR2immunoglobulin Fc fusion protein was used as it enabled ready binding of VEGFR2 to the protein A sensor chips of the BLItz machine in the correct orientation. Analysis of the association and dissociation data at a range of CPG2 concentrations indicated that p700 increased the affinity of CPG2 for VEGFR2 by about 100-fold, with a calculated dissociation constant (Kd) of $130 \mathrm{nM}$ compared to $15 \mu \mathrm{M}$ for CPG2 alone. A representative experiment, at a single protein concentration, is shown in Figure 5. This confirmed that p700 facilitates high affinity binding of CPG2 to VEGFR2. 


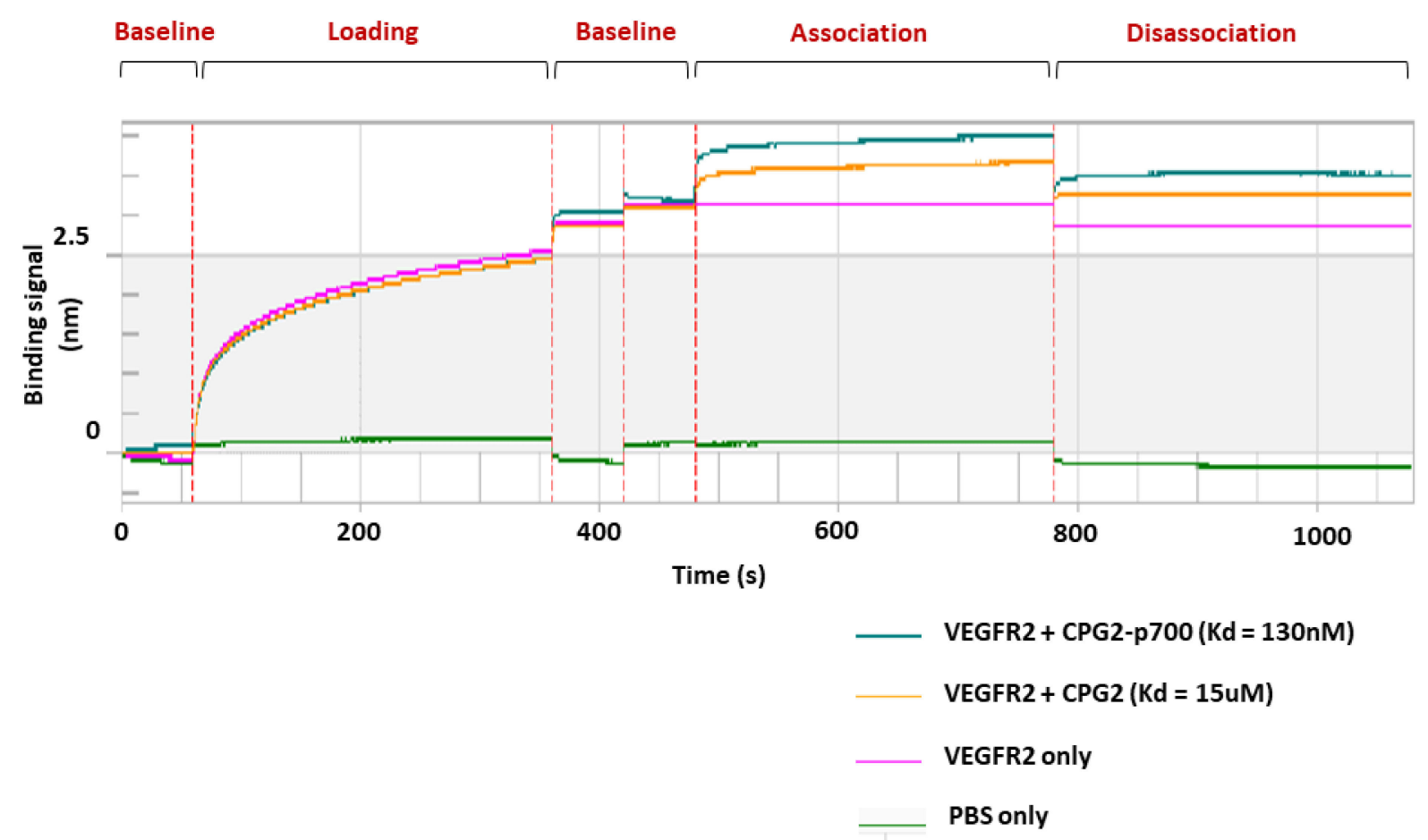

Figure 5. A representative biolayer interferometry experiment comparing the interaction between recombinant CPG2 or CPG2-p700 and VEGFR2. The binding signal is the wavelength shift detected by the BLItz machine and corresponds to the change in thickness of the biolayer as a result of the interaction between the recombinant proteins (CPG2 or CPG2-p700) and a VEGFR2-coated biosensor and is plotted against the duration of the interactions. Four runs are shown with PBS only loaded (green line), VEGFR2 only loaded (purple line) and VEGFR2 loaded followed by CPG2 (yellow line) or CPG2-p700 (green line). The first loading curve is the binding of VEGFR2-Fc to the protein A coated sensor. The sensor was then washed by dipping into PBS (baseline) before dipping into the CPG2 protein solutions (association). The sensor was then transferred to PBS and dissociation measured. Binding affinity (dissociation constant, $\mathrm{Kd}$ ) was calculated using the BLItz software based on five repeats using increasing concentrations (300 $\mathrm{nM}$ to $10 \mathrm{mM}$ ) of recombinant proteins. CPG2-p700 showed a 100-fold increase in binding affinity compared with CPG2.

3.6. Cytotoxicity Assays to Determine the Ability of Recombinant CPG2 Proteins to Activate the ZD2676P Prodrug

The effectiveness of both CPG2 and CPG2-p700 to convert the nitrogen mustard prodrug, ZD2676P, into a cytotoxic drug, and thus kill 4T1 mouse breast tumour cells, was evaluated using an MTS cytotoxicity assay. Using a range of concentrations of the prodrug, based on a previous study [12], it was found that there was no significant difference in cell death between cells treated with ZD2676P alone or those treated with ZD2676P and CPG2 enzyme. However, at the highest dose of ZD2676P $(14 \mu \mathrm{M})$, there was a significant increase in cell death with cells treated with CPG2-p700, relative to both prodrug alone and prodrug with unlabelled CPG2 (Figure 6). 


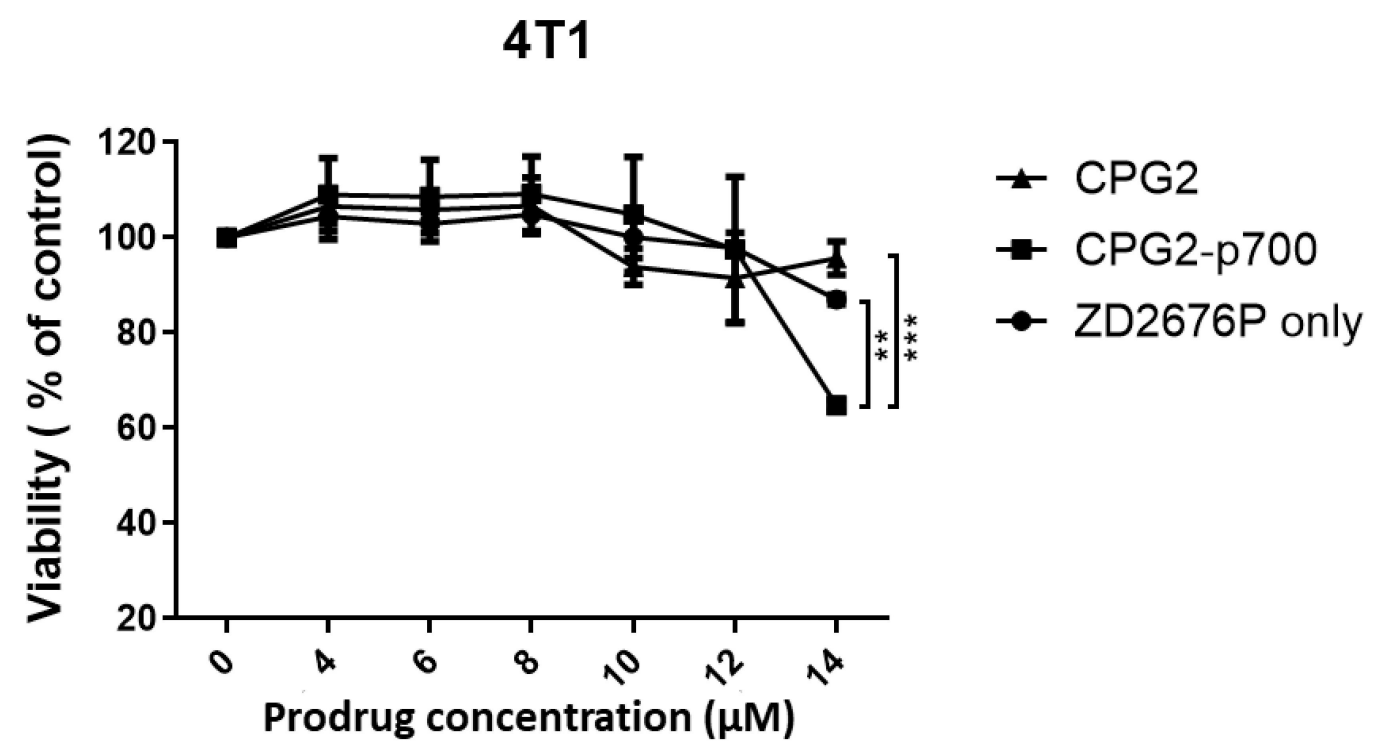

Figure 6. The effect of increasing concentrations of prodrug ZD2676P on the viability of the mouse breast cancer cell line $4 \mathrm{~T} 1$ in the presence or absence of CPG2 or CPG2-p700. Data are means \pm SEM; $n=3\left({ }^{* *}=p<0.01,{ }^{* * *}=p<0.001\right)$ indicates significance, two-way ANOVA, multiple comparison test.

\section{Discussion}

Drug toxicity is a major challenge for anticancer chemotherapeutics and is the reason for the wealth of studies investigating delivery strategies that might suppress the toxic side effects of conventional drugs [13]. CPG2 is sometimes used in the clinic to reduce excess concentration of methotrexate in cancer patients by converting it into 4-deoxy-4amino-N10-methylpteroic acid (DAMPA) and glutamate, which are both non-toxic and metabolised by the liver [14], and so is known to be safe in the clinic. CPG2 is also the only enzyme that has been tested in ADEPT clinical trials, which were not altogether successful [3].

We reasoned that the use of p700 to target CPG2 or other enzymes to tumour sites, rather than antibodies, could overcome some of the issues associated with these ADEPT trials, by potentially reducing immunogenicity, decreasing clearance times and decreasing potential drug resistance due to the ability of p700 to target multiple receptors [11]. Nevertheless, whether p700 would retain its ability to bind receptors once covalently coupled to an enzyme could only be determined empirically.

While there are several small molecule drugs that also target a wider family of tyrosine kinase receptors, such as sorafenib and sunitinib, these all target the intracellular kinase domain and can also target other intracellular kinases with the potential for off-target effects. Extracellular, competitive inhibitors of these receptors may decrease the likelihood of side-effects and also offer the potential to act as ligands for targeted drug delivery.

Previous data from our laboratory had shown that $p 700$ could potently inhibit tumour growth in a syngeneic breast tumour model [11]. However, on its own, the molecule is not cytotoxic, and tumours were found to regrow following treatment cessation or prolonged treatment (unpublished observation). This fuelled the idea that, in addition to inhibiting target receptors, p700 might be used as a delivery vehicle to target cytotoxic drugs to tumour sites, potentially enhancing the therapeutic potential of p700 while decreasing the off-target effects of chemotherapy.

As such, we coupled p700 to the N-terminus of CPG2 via a $\left[\mathrm{Gly}_{4} \mathrm{Ser}\right]_{4}$ linker and showed that it could be purified from the insoluble fraction of bacteria in a form that retained both the catalytic activity of the CPG2 enzyme, as determined by methotrexate cleavage, and also the ability of p700 to bind to VEGFR2 with a high affinity, as determined by BLI. Additionally, p700 helped localise CPG2 to the surface of 4T1 tumour cells, increasing cytotoxicity in the presence of the ZD2676P prodrug. 
Although we only tested binding of the CPG2-p700 complex to VEGFR2 (the target of the TIMP3 parent protein), and not the other closely related target receptors of p700, it would seem likely that this wider receptor binding profile is indeed retained, not only because these other receptors share a very similar ligand binding site in their D2/D3 immunoglobulin-like domains but also due to the fact that p700 appeared to effectively localise CPG2 to the surface of $4 \mathrm{~T} 1$ cells, which do not express significant levels of VEGFR2 [15]; however, they do express VEGFR1 [16] and FGF receptors [17].

Although the improved ability CPG2-p700 to activate the pro-drug in the cytotoxicity assay, relative to CPG2 alone, was only seen at the highest dose of pro-drug, these concentrations were based on those from a previous study using a human colorectal cancer cell line and had not been optimised for 4T1 cells. A greater difference between the uncoupledand p700-coupled CPG2 may have been seen if a higher dose range had been assessed. 4T1 is a highly metastatic breast cancer cell line that is very resistant to cytotoxic drugs [18], and so this lower level of sensitivity is not surprising. In this case, 4T1 cells were chosen as their growth in mice had previously been shown to be sensitive to the p700 peptide (although the peptide alone is not cytotoxic) [11], enabling future drug testing in vivo. Effective cell killing of these cells via p700-CPG2 is, therefore, a very robust test of its efficacy. Clearly, it will be important to reassess this efficacy on human tumour cells. However, the p700 region of TIMP3 does indeed bind to multiple pro-angiogenic growth factor receptors on human cells [11], and because it is totally conserved between mice and humans, it is also highly unlikely to be immunogenic in either species. Moreover, we have recently shown that p700 can effectively deliver liposomal doxorubicin to MCF7 human breast cancer cells [19]

While p700 is much less likely to elicit an immune response than a non-humanised monoclonal antibody, it is unlikely to reduce the potential immunogenicity of CPG2 itself. Nevertheless, our understanding of immunogenic epitopes is constantly improving, and it is possible to predictively "deimmunise" proteins, as has been shown for certain $\beta$ lactamases that have applications in ADEPT [20], so it is likely that immunogenicity of the enzyme may become less of an issue in the future.

\section{Conclusions}

The data presented here verify the feasibility of using p700 as an alternative to monoclonal antibodies in directing CPG2 to tumour cells, its key advantages being small size ( $<2 \mathrm{kDa}$ versus $150 \mathrm{kDa}$ ), lack of immunogenicity and multi-receptor binding. Moreover, we have shown that the CPG2-p700 fusion protein can be produced as a single functional protein in a bacterial expression system, hugely decreasing the potential production costs of such a molecule over ADEPT, where enzyme and antibody must be produced separately and chemically cross-linked, and where any antibody found to be effective in animal studies would need to be humanised prior to trials in humans.

Supplementary Materials: The following are available online, Supplementary Data, S1: Insertion of codon optimised CPG2 and CPG2-p700 into pET28a plasmid vector. Figure S1: Insertion of codon optimised CPG2 and CPG2-p700 into pET28a plasmid vector.

Author Contributions: M.S.A., Data curation, Formal analysis, Methodology, Validation and WritingOriginal draft. M.D.B., Investigation, Supervision and review and editing. F.A., Methodology. All authors have read and agreed to the published version of the manuscript.

Funding: This research was funded by the Saudi Arabian Cultural Bureau in London.

Institutional Review Board Statement: Not applicable.

Informed Consent Statement: Not applicable.

Data Availability Statement: The data presented in this study are available in Supplementary Materials.

Conflicts of Interest: The authors declare no conflict of interest.

Sample Availability: Samples of the compounds are not available from the authors. 


\section{References}

1. Chen, Y.; Jia, Y.; Song, W.; Zhang, L. Therapeutic potential of nitrogen mustard based hybrid molecules. Front. Pharmacol. 2018, 9, 1453. [CrossRef] [PubMed]

2. Sharma, S.K.; Bagshawe, K.D. Antibody directed enzyme prodrug therapy (ADEPT): Trials and tribulations. Adv. Drug Deliv. Rev. 2017, 118, 2-7. [CrossRef] [PubMed]

3. Sharma, S.K.; Bagshawe, K.D. Translating antibody directed enzyme prodrug therapy (ADEPT) and prospects for com-bination. Expert Opin. Biol. Ther. 2017, 17, 1-13. [CrossRef] [PubMed]

4. Sharma, S.K.; Bagshawe, K.D.; Melton, R.G.; Sherwood, R.F. Human immune response to monoclonal antibody-enzyme conjugates in ADEPT pilot clinical trial. Cell Biophys. 1992, 21, 109-120. [CrossRef] [PubMed]

5. Goda, S.K.; Rashidi, F.A.B.; Fakharo, A.A.; Al-Obaidli, A. Functional overexpression and purification of a codon optimized synthetic glucarpidase (carboxypeptidase G2) in Escherichia coli. Protein J. 2009, 28, 435-442. [CrossRef] [PubMed]

6. Rashidi, F.B.; AlQhatani, A.D.; Bashraheel, S.S.; Shaabani, S.; Groves, M.R.; Domling, A.; Goda, S.K. Isolation and molecular characterization of novel glucarpidases: Enzymes to improve the antibody directed enzyme pro-drug therapy for cancer treatment. PLoS ONE 2018, 13, e0196254. [CrossRef] [PubMed]

7. Malekshah, O.M.; Chen, X.; Nomani, A.; Sarkar, S.; Hatefi, A. Enzyme/prodrug systems for cancer gene therapy. Curr. Pharmacol. Rep. 2016, 2, 299-308. [CrossRef] [PubMed]

8. Krackhardt, A.; Schwartz, S.; Thiel, E. Targeting folates by carboxypeptidase G2: Potential applications in anticancer therapy. Onkologie 2000, 23, 538-543. [CrossRef] [PubMed]

9. Jeyaharan, D.; Brackstone, C.; Schouten, J.; Davis, P.; Dixon, A.M. Characterisation of the carboxypeptidase G2 catalytic site and design of new inhibitors for cancer therapy. Chembiochemistry 2018, 19, 1959-1968. [CrossRef] [PubMed]

10. Slastnikova, T.A.; Ulasov, A.V.; Rosenkranz, A.A.; Sobolev, A.S. Targeted intracellular delivery of antibodies: The state of the art. Front. Pharmacol. 2018, 9, 1208. [CrossRef] [PubMed]

11. Chen, Y.-Y.; Brown, N.J.; Jones, R.; Lewis, C.E.; Mujamammi, A.H.; Muthana, M.; Seed, M.; Barker, M.D. A peptide derived from TIMP-3 inhibits multiple angiogenic growth factor receptors and tumour growth and inflammatory arthritis in mice. Angiogenesis 2013, 17, 207-219. [CrossRef] [PubMed]

12. Blakey, D.C.; Burke, P.J.; Davies, D.H.; Dowell, R.I.; East, S.J.; Eckersley, K.P.; Flitton, J.E.; McDaid, J.; Melton, R.G.; NiculescuDuvaz, I.A.; et al. ZD2767, an improved system for anti-body-directed enzyme prodrug therapy that results in tumor regressions in colorectal tumor xenografts. Cancer Res. 1996, 56, 3287-3292. [PubMed]

13. Dadwal, A.; Baldi, A.; Narang, R.K. Nanoparticles as carriers for drug delivery in cancer. Artif. Cells Nanomed. Biotechnol. 2018, 46, 295-305. [CrossRef] [PubMed]

14. Green, J.M. Glucarpidase to combat toxic levels of methotrexate in patients. Ther. Clin. Risk Manag. 2012, 8, 403-413. [CrossRef] [PubMed]

15. Tseng, W.W.; Winer, D.; Kenkel, J.A.; Choi, O.; Shain, A.H.; Pollack, J.R.; French, R.; Lowy, A.M.; Engleman, E.G. Development of an orthotopic model of invasive pancreatic cancer in an immunocompetent murine host. Clin Cancer Res. 2010, 16, 3684-3695. [CrossRef] [PubMed]

16. Wu, Y.; Hooper, A.T.; Zhong, Z.; Witte, L.; Bohlen, P.; Rafii, S.; Hicklin, D.J. The vascular endothelial growth factor receptor (VEGFR-1) supports growth and survival of human breast carcinoma. Int. J. Cancer 2006, 119, 1519-1529. [CrossRef] [PubMed]

17. Ye, T.; Wei, X.; Yin, T.; Xia, Y.; Li, D.; Shao, B.; Song, X.; He, S.; Luo, M.; Gao, X.; et al. Inhibition of FGFR signaling by PD173074 improves antitumor immunity and impairs breast cancer metastasis. Breast Cancer Res. Treat. 2014, 143, 435-446. [CrossRef] [PubMed]

18. Lasso, P.; Murcia, M.L.; Sandoval, T.A.; Urueña, C.; Barreto, A.; Fiorentino, S. Breast tumor cells highly resistant to drugs are controlled only by the immune response induced in an immunocompetent mouse model. Integr. Cancer Ther. 2019, 18. [CrossRef] [PubMed]

19. Aldughaim, M.S.; Muthana, M.; Alsaffar, F.; Barker, M.D. Specific targeting of PEGylated liposomal doxorubicin (Dox-il((R))) to tumour cells using a novel TIMP3 peptide. Molecules 2020, 26.

20. Osipovitch, D.C.; Parker, A.S.; Makokha, C.D.; Desrosiers, J.; Kett, W.C.; Moise, L.; Bailey-Kellogg, C.; Griswold, K.E. Design and analysis of immune-evading enzymes for ADEPT therapy. Protein Eng. Des. Sel. 2012, 25, 613-623. [CrossRef] [PubMed] 